\title{
Prevalence of Anaemia in a Tertiary Care Hospital in Hyderabad, Telangana, India
}

\author{
K.S. Saraswathi ${ }^{1}$ and R. Shyamala ${ }^{2^{*}}$ \\ ${ }^{1}$ Department of Obstetrics \& Gynaecology, Shadan Institute of Medical Sciences \& P.G \\ Research Institute, Hyderabad, Telangana, India \\ ${ }^{2}$ Department of Microbiology, Malla Reddy Medical College for Women, Hyderabad \\ Telangana, India
}

*Corresponding author

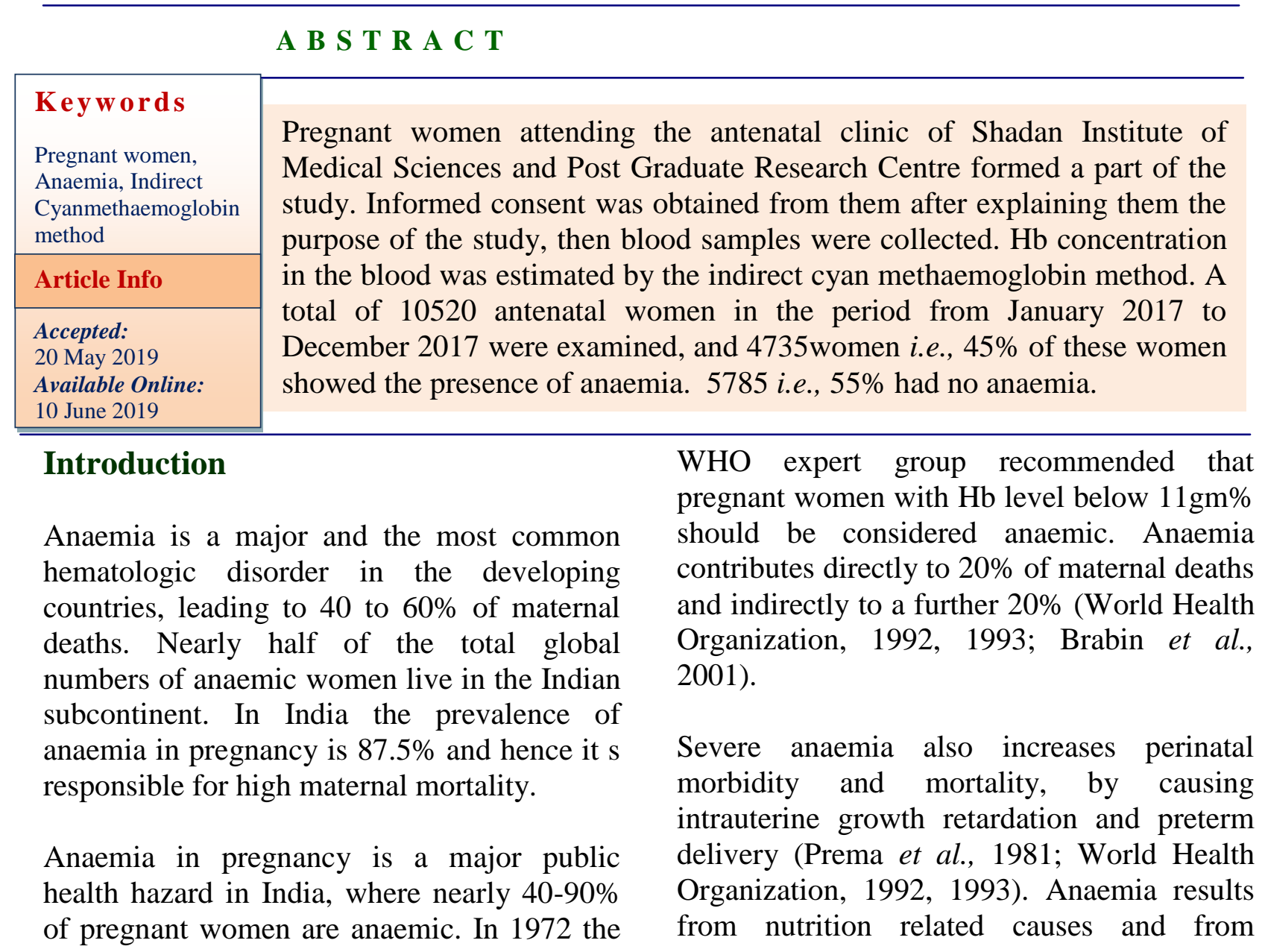


inflammatory or infectious diseases, worm infestations and from blood loss. Iron deficiency anaemia resulting from inadequate intake and low absorption of dietary iron is the most common form of anaemia in India (Seshadri et al., 1994, 1997). India launched the National Nutritional Anaemia Prophylaxis Programme (NNAPP) in 1970. Under this programme, iron and folic acid tablets are distributed to pregnant women. The present study reports the prevalence of anaemia among pregnant women in a tertiary care hospital.

\section{Materials and Methods}

Pregnant women attending the antenatal clinic of Shadan Institute of Medical Sciences and Post Graduate Research Centre formed a part of the study. Informed consent was obtained from them after explaining them the purpose of the study, then blood samples were collected. $\mathrm{Hb}$ concentration in the blood was estimated by the indirect cyan methaemoglobin method (Seshadri et al., 1994, 1997; Sood et al., 1975). Anaemia was assessed according to WHO criteria(8). A $\mathrm{Hb}$ concentration of less than $11 \mathrm{gm} \%$ was considered an indication of anaemia. $\mathrm{Hb}$ concentration of less than $7 \mathrm{gm} \%, 7-8 \mathrm{gm} \%$, and $8-11 \mathrm{gm} \%$ were considered to indicate severe, moderate and mild anaemia respectively.

\section{Results and Discussion}

A total of 10520 antenatal women in the period from January 2017 to December 2017 were examined, and 4735 women i.e., $45 \%$ of these women showed the presence of anaemia. $56 \%$ had no anaemia.

Among the 4735 patients diagnosed with Anaemia, 238 patients (5\%) had Severe anaemia.

1562 patients (33\%) had Moderate anaemia, 2935 patients (62\%) had mild Anaemia.

The prevalence of anaemia among pregnant women was $45 \%$. The National Family health Survey 2 NFHS-2 conducted during 1998-99 found an overall prevalence of $49.7 \%$ among 5654 pregnant women from 25 states [National Family Health Survey (NFHS-2)]. Anaemia remains endemic among pregnant women in India despite intervention measures such as the distribution of 100 folifer tabs (containing $100 \mathrm{mgm}$ of elemental iron and 500 ug of folic acid) to each woman to be taken during pregnancy (Table 1 and 2).

Table.1

\begin{tabular}{|l|l|}
\hline $\begin{array}{l}\text { Total number of Patients } \\
\text { Tested for Anaemia }\end{array}$ & $\mathbf{1 0 , 5 2 0}$ patients \\
\hline Patients Having Anaemia & $\begin{array}{l}4735 \text { patients having } \\
\text { anaemia }(45 \%)\end{array}$ \\
\hline Patients with no Anaemia & 5785 patients $(55 \%$ \\
\hline
\end{tabular}

Table.2

\begin{tabular}{|l|l|}
\hline Type of Anaemia & Number of Patients \\
\hline Severe Anaemia & 238 patients $(5 \%)$ \\
\hline Moderate Anaemia & 1562 patients $(33 \%)$ \\
\hline Mild Anaemia & 2935 patients $(62 \%)$ \\
\hline
\end{tabular}




\section{Chart.1}

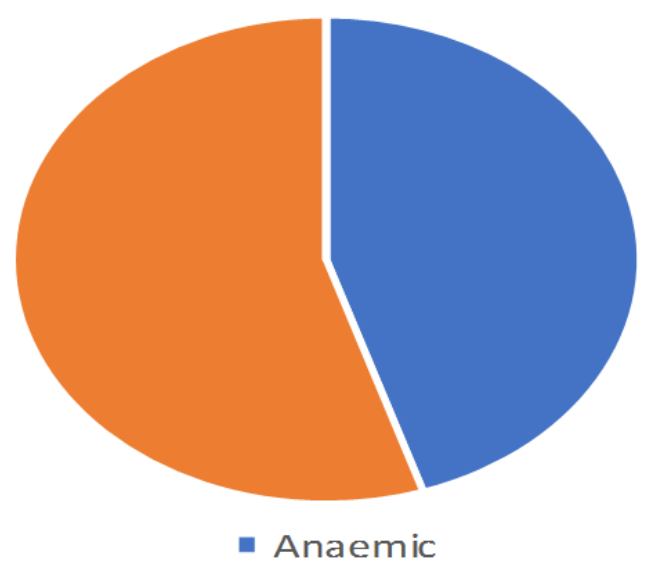

\section{Incidence of Anaemia}

Some of the reasons that iron supplementation programs are ineffective may be that the programs do not always reach the target people, health staff are inadequately trained and mobilized to ensure the effective distribution of supplements, and compliance is low, due, in particular, to the side effects associated with iron supplements (ICMR Task Force Study) (Stoltzfus, 2001). The overall prevalence of severe anaemia among pregnant women was $13.1 \%$. A prevalence of $8.3 \%$ for severe anaemia has been reported among pregnant women in the slumps of Hyderabad (Raman et al., 1989). In rural and Urban areas in Punjab the prevalence of severe anaemia was as high as $56 \%$ in a population based survey.

In conclusion, nutritional anaemia can be prevented by taking proper diet and also taking iron supplements. Regular hemoglobin check and good care of pregnant women i.e, by giving iron supplements to them will prevent nutrional anaemia in pregnancy.

\section{References}

Brabin, BJ., M. Hakimi, et al., J Nutr 2001; 131(2S-2):604S-15S
ICMR Task Force Study. Evaluation of the National Nutritional Anaemia Prophylaxis Programme. New Delhi: Indian Council of Medical Research, 1989

ICMR Task Force Study. Evaluation of the National Nutritional Anaemia Prophylaxis Programme. New Delhi: Indian Council of Medical Research, 1989

NFHS-2. National Family Health Survey (NFHS-2), 1998-1999, India. Mumbai: Indian Institute of Population Studies, 2000

Prema, K., et al., Nutr Rep Int 1981; 23: 63743

Raman, L, et al., Nutr Rep Int 1989; 39: 7380.

Seshadri, S. et al., Malnutrition in South Asia: A regional profile. UNICEF Regional Office for South Asia, 1997:75-124.

Seshadri, S., K. Sharma et al., Iron supplementation to control pregnancy anaemia. Proc Nutr Soc India 1994; 41: 131-40.

Sood, SK, K Ramachandran, et al., W.H.O sponsored collaborative studies on nutritional anaemia in India. QJ Med 1975; 44: 241-58. 
Stoltzfus, R J. J. Nutr 2001; 131 (2S-2): 565S$7 \mathrm{~S}$.

World Health Organization. Prevention and management of anaemia in pregnancy. WHO/FHE/MSM/93.5 Geneva: WHO,
1993.

World Health Organization. The prevalence of anaemia in women. WHO/MCH/MSM/92.2. Geneva: WHO, 1992.

\section{How to cite this article:}

Saraswathi, K.S. and Shyamala, R. 2019. Prevalence of Anaemia in a Tertiary Care Hospital in Hyderabad, Telangana. Int.J.Curr.Microbiol.App.Sci. 8(06): 2568-2571. doi: https://doi.org/10.20546/ijcmas.2019.806.309 